\title{
Preparation of environmentally resistant conductive silica-based polymer hybrids containing tetrathiafulvalene-tetracyanoquinodimethane charge-transfer complexes
}

\author{
Hiroshi Okada ${ }^{1,2}$, Kazuo Tanaka ${ }^{1}$ and Yoshiki Chujo ${ }^{1}$ \\ We report the preparation of conductive glasses based on organic -inorganic hybrids that contain charge-transfer (CT) \\ complexes of tetrathiafulvalene (TTF) and 7,7,8,8-tetracyanoquinodimethane (TCNQ). Using poly(vinylpyrrolidone) as the \\ organic component, the hybrid materials were prepared with various concentrations of CT complexes. From a series of \\ evaluations, including light absorption and X-ray diffraction (XRD) measurements and microscopy observations, it was confirmed \\ that CT complexes form in the materials and are well dispersed. The hybrids that were synthesized with relatively large loading \\ amounts of CT complexes exhibited a conductivity level similar to that of a semiconductor $\left(\sim 10^{-1} \mathrm{~S} \mathrm{~cm}^{-1}\right)$. In addition, the \\ conductivity of the synthesized hybrids was maintained during heating and changed negligibly after exposure to water. \\ Polymer Journal (2014) 46, 800-805; doi:10.1038/pj.2014.67; published online 23 July 2014
}

\section{INTRODUCTION}

Organic-inorganic polymer hybrids are mixtures that contain a polymer and an inorganic compound with a domain size at the nano or molecular scale. ${ }^{1}$ By processing a polymer into a hybrid with silicate, a robust material can be obtained without loss of polymer functionalities. ${ }^{2}$ Because of their transparency and enhanced stability, various types of thermally stable emissive hybrids can be obtained using optically functionalized polymers that have relatively low durabilities. $^{3}$ In addition, by immobilizing unstable or transient structures within the matrices, unique characteristics can be observed in the hybrids that originate from these structures. ${ }^{4}$ Although the silica component generally functions as an insulator, there are several examples of silica-based conductive hybrids ${ }^{5-9}$ and composites. ${ }^{10-15}$ Stability can be significantly enhanced by hybrid formation, although a decrease in conductivity is often observed. Thus, the development of conductive hybrids with environmental resistance remains a challenge.

Tetrathiafulvalene (Scheme 1, TTF)-based polymer composites are a promising platform for developing advanced opto- and/or electronic materials. ${ }^{16-19}$ These materials can be prepared using a facile solution process, and have shown a similar level of conductivity $\left(<10^{-2} \mathrm{~S} \mathrm{~cm}^{-1}\right)$ to that of TTF conductive films composed of mixed-valence TTF crystals. ${ }^{20}$ Following the first report of TTFcontaining conductive composites in $1981,{ }^{21}$ detailed information about the characteristics of TTF species and the properties of TTF films have been reported. ${ }^{22-26}$ Several applications have recently been presented based on TTF-based polymer composites for practical uses, such as transparent conductive materials and flexible conductors. ${ }^{27}$ Regulation of the radical concentration in the film through photopatterning and long-term storage of radical spins in the film have also been achieved, although conductivity was below the detection limit in these films. ${ }^{28,29}$ In addition, it has been demonstrated that conductivity can be tuned by modulating the morphologies, ${ }^{27}$ additives, ${ }^{30}$ substituents, ${ }^{31}$ moisture, ${ }^{32}$ preparation conditions ${ }^{33}$ and matrix type. ${ }^{34,35}$ Finally, an improvement in conductivity compared with that of TTF crystals has been achieved through condensation of the TTF species at the film surface. ${ }^{34}$ By conjugation to silica, the formation of highly ordered structures has been demonstrated. ${ }^{36-40}$ Despite the usability and versatility of TTF polymer composites, there is considerable room to increase the environmental resistance of TTF polymer composites. For example, as shown in our previous work, the conductivity of these composites decreases after heating at temperatures of $>80^{\circ} \mathrm{C}$ for several minutes. ${ }^{28}$ The next challenge is to develop robust TTF-based conductive materials using a facile preparation method.

Herein, we present conductive glasses with environmental resistance based on organic-inorganic hybrids containing TTF and 7,7,8,8-tetracyanoquinodimethane (TCNQ) complexes. By using poly(vinylpyrrolidone) (PVP) as the polymer component, hybrid materials were prepared with various concentrations of CT complexes. Through a series of measurements, the formation of the CT complexes and their dispersion states were investigated. We initially observed that these hybrids exhibit conductivity at a level similar to that of a semiconductor $\left(\sim 10^{-1} \mathrm{~S} \mathrm{~cm}^{-1}\right)$. In addition, the change in 
conductivity was monitored during heating and during dipping into water. The synthesized hybrids exhibited high stability against environmental changes. To the best of our knowledge, this is the first study to present a facile strategy for synthesizing conductive glasses with environmental resistance for use in organic conductive materials.

\section{EXPERIMENTAL PROCEDURE}

\section{General}

The electrical conductivity of the casting films was measured using the fourprobe technique at $25^{\circ} \mathrm{C}$. Scanning electron microscopy images were acquired using a JEOL JSM-5600 (JEOL Ltd., Tokyo, Japan) operated at an accelerating voltage of $15 \mathrm{kV}$. Ultraviolet-visible-near infrared absorption spectra were recorded using a SHIMADZU UV-3600 ultraviolet-visible-near infrared spectrophotometer and a JASCO V-570 spectrophotometer (JASCO Co., Tokyo, Japan). Powder X-ray diffraction (XRD) patterns were recorded on a SHIMADZU X-ray diffractometer-6000 (SHIMADZU Co., Ltd., Kyoto, Japan) using high-intensity $\mathrm{Cu} \mathrm{K} \alpha$ radiation from the $2 \theta$ range of $2-90^{\circ}$ at a scan rate of $0.02^{\circ} \mathrm{s}^{-1}$. Powder samples for the XRD measurements were prepared by curetting the materials. Thermogravimetric analysis was performed on an EXSTAR TG/DTA 6220, Seiko Instruments Inc., Chiba, Japan, with a heating rate of $10^{\circ} \mathrm{C}$ per min up to $500^{\circ} \mathrm{C}$ under a nitrogen atmosphere. Residual chloroform was removed by heating the samples in a vacuum oven at $100^{\circ} \mathrm{C}$ for $1 \mathrm{~h}$ before thermogravimetric analysis measurements. TTF, TCNQ and acetic acid were purchased from Wako Pure Chemical Industries, Ltd., Osaka, Japan. PVP $\left(M_{\mathrm{w}}=630000\right)$ was purchased from Tokyo Kasei Kogyo Co., Ltd., Tokyo, Japan. Methyltrimethoxysilane (MeTMOS) was purchased from SigmaAldrich, Inc., St Louis, MO, USA. These reagents were used without further purification.

\section{Preparation of TTF-TCNQ complexes}

To a solution of TTF $(165 \mathrm{mg}, 0.81 \mathrm{mmol})$ in acetonitrile $(50 \mathrm{ml})$, TCNQ ( $165 \mathrm{mg}, 0.81 \mathrm{mmol})$ in acetonitrile $(250 \mathrm{ml})$ was added, and the mixture was stirred for $1 \mathrm{~h}$ at room temperature. ${ }^{41}$ The black precipitate was filtered and washed with acetonitrile. The product was directly used in the next step.

\section{Preparation of PVP-silica hybrid films doped with various} amounts of TTF-TCNQ complexes

Hybrid films doped with TTF-TCNQ complexes were prepared via the acidcatalyzed sol-gel reaction of MeTMOS in the presence of a $0.38 \mathrm{M} \mathrm{CH}_{3} \mathrm{COOH}$ aqueous solution. PVP was dissolved in methanol $\left(40 \mathrm{gl}^{-1}\right)$, and $\mathrm{CH}_{3} \mathrm{COOH}$ and MeTMOS were added. After stirring for $5 \mathrm{~min}$, various amounts of TTF-TCNQ complexes were added to the reaction solution, and the sample was subsequently stirred at ambient temperature for $5 \mathrm{~min}$. The reaction solution was poured into a polypropylene vessel and then heated in an oven at $60{ }^{\circ} \mathrm{C}$ for 2 days. Black hybrid films were prepared. The names used for the samples consist of the percentage weight of glass contributed by PVP (HYB)

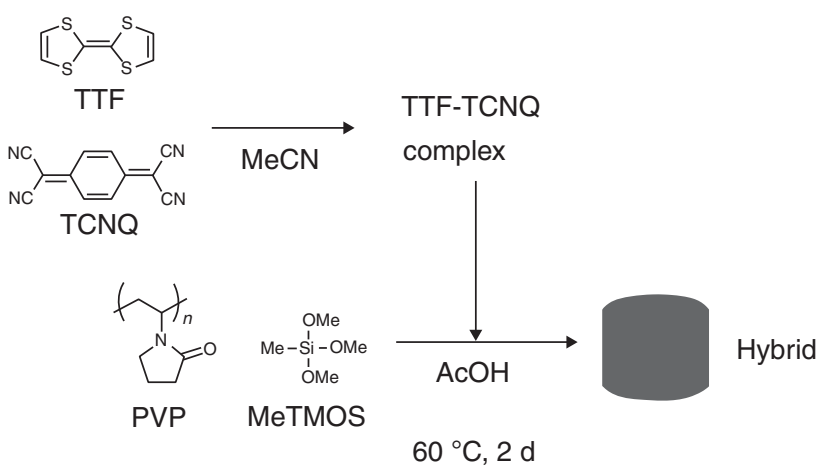

Scheme 1 Chemical structures and the preparation of the hybrids used in this study and the percentage weight of the material contributed by the TTF-TCNQ complexes (TT) (for example, HYB13TT16 is composed of $13 \mathrm{wt} \%$ of glass containing $16 \mathrm{wt} \%$ of the complexes).

\section{Conductivity measurements}

The surface conductivity was determined using the four-point probe method. To monitor the time courses of the conductivity changes, the samples were placed on a hot plate and the conductivity was recorded by altering the surface temperature. To evaluate the durability in water, the samples were dipped into deionized water. The conductivity was measured after drying under ambient conditions.

\section{RESULTS AND DISCUSSION}

The general procedure for preparing the hybrids is described here according to our previous paper. ${ }^{4}$ Charge-transfer (CT) complexes were isolated from the mixture of TTF and TCNQ in acetonitrile and used directly in the next step. Hybrid materials doped with the resultant TTF-TCNQ complexes were prepared via the acid-catalyzed sol-gel reaction of MeTMOS using a $0.38 \mathrm{M}$ aqueous acetic acid solution. The feed ratios are listed in Table 1. PVP was dissolved in methanol $\left(40 \mathrm{gl}^{-1}\right)$, and a $0.38 \mathrm{M}$ acetic acid solution and MeTMOS were added. After stirring for $5 \mathrm{~min}$, various amounts of TTF-TCNQ complexes were added to the PVP solution. The solution was ultrasonicated for $5 \mathrm{~min}$ and subsequently stirred for $5 \mathrm{~min}$. The reaction solution was poured into a polypropylene vessel and then heated in an oven at $60^{\circ} \mathrm{C}$ for 2 days. Black self-supporting films were obtained (Figure 1). The feed ratios of TTF-TCNQ complexes, PVP and silica are shown in Table 1 . When the amount of TTF-TCNQ complexes was increased, the film formability decreased, although all of the samples had measurable electronic properties. The environment responsiveness of the hybrids was evaluated using the hybrids containing 16 wt $\%$ TTF-TCNQ complexes.

Table 1 Preparation of TTF-TCNQ complexes containing hybrid films

\begin{tabular}{lcccc}
\hline & $\begin{array}{c}\text { TTF-TCNQ complex } \\
(\mathrm{mg})\end{array}$ & $\begin{array}{c}\text { MeTMOS } \\
(\mathrm{ml})\end{array}$ & $\begin{array}{c}\mathrm{PVP} / \mathrm{MeOH} \\
(\mathrm{ml})\end{array}$ & $\begin{array}{c}\mathrm{CH}_{3} \mathrm{COOH}_{a q} \\
(\mathrm{ml})\end{array}$ \\
\hline HYB50TT00 & - & 0.12 & 1.42 & 0.053 \\
HYB50TT01 & 1.0 & 0.12 & 1.42 & 0.053 \\
HYB50TT08 & 9.1 & 0.12 & 1.42 & 0.053 \\
HYB50TT16 & 18.3 & 0.12 & 1.42 & 0.053 \\
HYB50TT24 & 27.3 & 0.12 & 1.42 & 0.053 \\
HYB50TT32 & 36.5 & 0.12 & 1.42 & 0.053 \\
HYB50TT40 & 54.8 & 0.12 & 1.42 & 0.053 \\
HYB00TT16 & 18.3 & - & 2.84 & 0.106 \\
HYB13TT16 & 18.3 & 0.03 & 2.47 & 0.092 \\
HYB25TT16 & 18.3 & 0.06 & 2.13 & 0.080 \\
HYB37TT16 & 18.3 & 0.09 & 1.79 & 0.067 \\
HYB50TT16 & 18.3 & 0.12 & 1.42 & 0.053 \\
\hline
\end{tabular}

Abbreviations: MeTMOS, methyltrimethoxysilane; PVP, poly(vinylpyrrolidone); TTF-TCNQ, tetrathiafulvalene-7,7,8,8-tetracyanoquinodimethane.

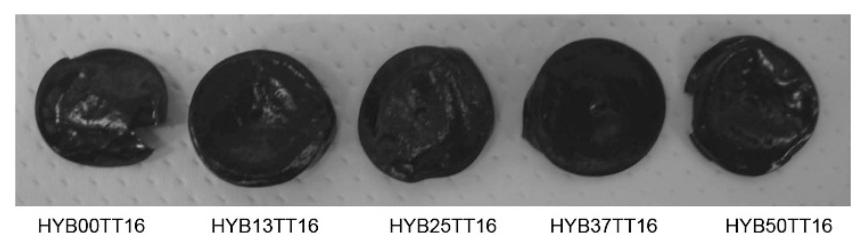

Figure 1 Appearance of the hybrids. A full color version of this figure is available at Polymer Journal online. 


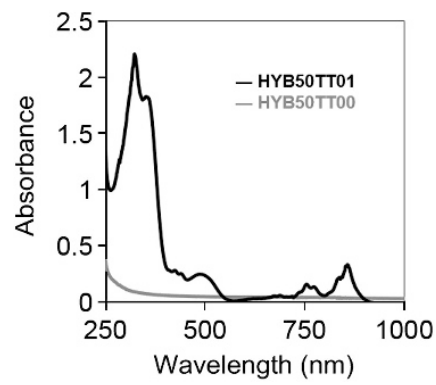

Figure 2 Ultraviolet-visible (UV-vis) spectra of hybrid films containing tetrathiafulvalene-7,7,8,8-tetracyanoquinodimethane (TTFTCNQ) complexes (HYB50TT01, black line) and not containing these complexes (HYB50TT00, gray line).
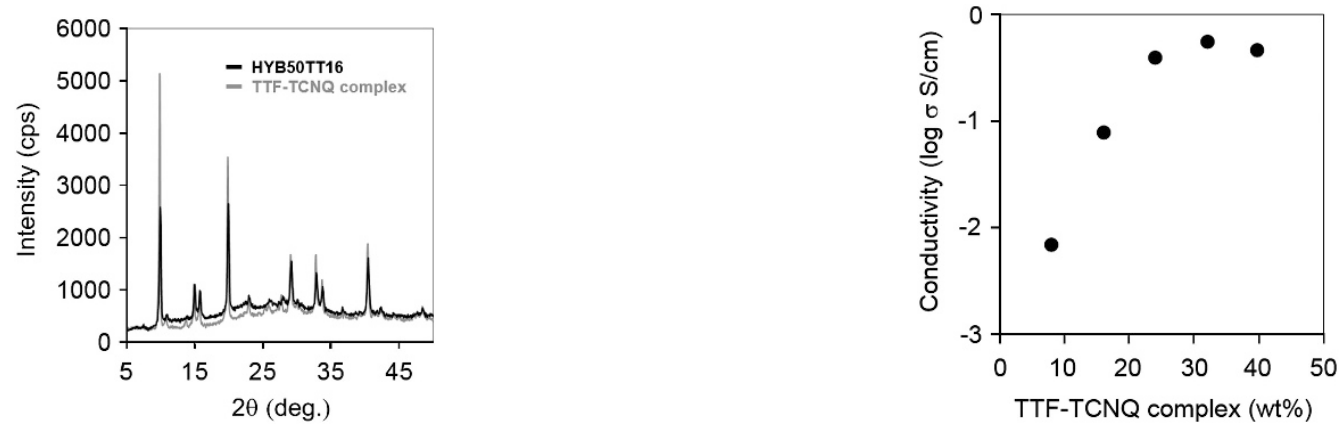

Figure 3 X-ray diffraction (XRD) patterns of tetrathiafulvalene-7,7,8,8tetracyanoquinodimethane (TTF-TCNQ) complexes (grey line) and of the hybrid films (black line).

To confirm the formation of CT complexes in the hybrids, the optical properties of the synthesized hybrids were examined. The absorption of the hybrid films was investigated by ultraviolet-visible spectroscopy. Figure 2 shows the spectra of the hybrids (HYB50TT01). To differentiate the peak positions and shapes of the hybrids, the spectra of the hybrids with a low concentration of TTF-TCNQ complexes were compared with that of the crystals. A spectrum that was almost identical to that of the TTF-TCNQ complex suspended in acetonitrile was obtained. ${ }^{41}$ Peaks representative of TTF-TCNQ CT complexes (390, 750 and $850 \mathrm{~nm}$ ) were obtained from the hybrid, and the shapes of these peaks were similar to those of the pure crystals. ${ }^{41}$ These data indicate that TTF-TCNQ complexes were maintained in the hybrids. Figure 3 shows the XRD patterns of crystals of TTF-TCNQ complexes and of

5 Conductivities of the hybrids containing various amounts of tetrathiafulvalene-7,7,8,8-tetracyanoquinodimethane (TTF-TCNQ) complexes (wt\%). The thicknesses of the films were $0.08-0.20 \mathrm{~mm}$.

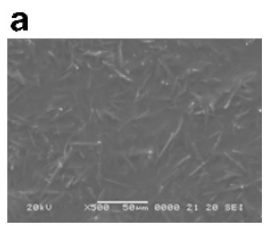

HYB50TT08

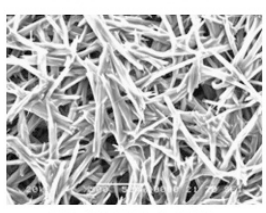

HYB50TT40

b

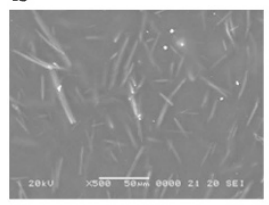

HYB00TT16

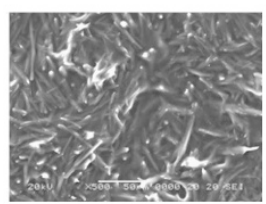

HYB50TT16

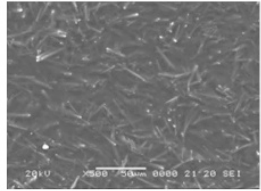

HYB50TT16

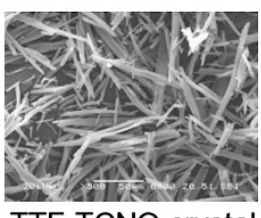

TTF-TCNQ crystal

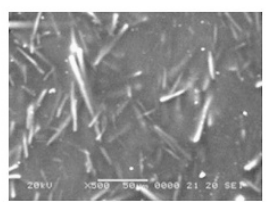

HYB13TT16

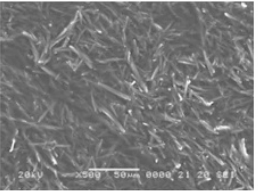

HYB50TT24

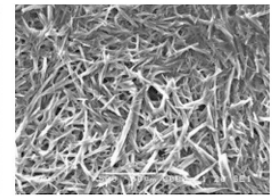

HYB50TT32

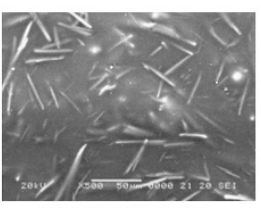

HYB25TT16

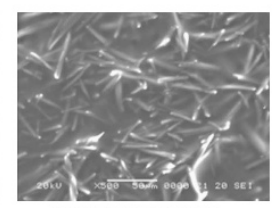

HYB37TT16

Figure 4 Scanning electron microscopy (SEM) images of the hybrid films (a) with various concentrations of tetrathiafulvalene-7,7,8,8tetracyanoquinodimethane (TTF-TCNQ) complexes and (b) with same concentration of the complexes and different ratios between organic and inorganic components. The scale bars represent $50 \mu \mathrm{m}$. 
the hybrids containing TTF-TCNQ complexes. Sharp peaks were observed from the hybrids. In particular, almost identical peak patterns were obtained from both samples. These data also indicate that TTF-TCNQ complexes were maintained in the hybrids.

The surface morphology was investigated using scanning electron microscopy imaging (Figure 4). The formation of nanofiber structures was observed in the TTF-TCNQ complex-containing composites (Figure 4a). Correspondingly, the synthesized hybrids containing TTF-TCNQ complexes exhibited fiber structures at the surface. Moreover, by increasing the amount of TTF-TCNQ complex in the material, the number of fiber structures clearly increased at the surface. These data clearly indicate that nanofibers based on CT complexes form in the hybrids. Furthermore, from the comparison

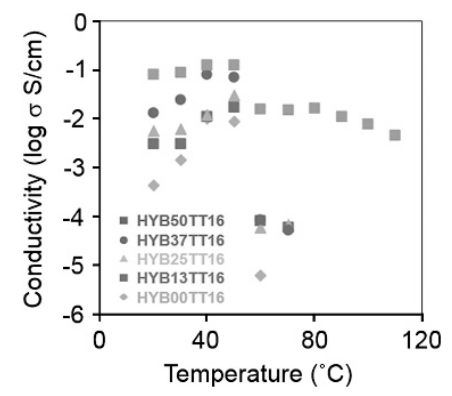

Figure 6 Dependencies of the conductivities of the hybrids on temperature. The thicknesses of the films were $0.16-0.19 \mathrm{~mm}$.

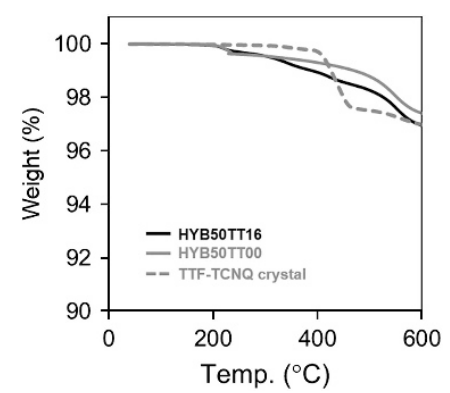

Figure 7 Thermogravimetric analysis (TGA) thermograms of the tetrathiafulvalene-7,7,8,8-tetracyanoquinodimethane (TTF-TCNQ) crystals and of the hybrids with a heating rate of $10^{\circ} \mathrm{C}$ per min under a nitrogen atmosphere. study with various amounts of the glass component, it was observed that the nanofiber structures were well developed and entangled at the surface of hybrids with a larger percentage of the glass component (Figure 4b). It is hypothesized that the TTF-TCNQ component is condensed at the surface of the material because of the low compatibility of the TTF-TCNQ complexes with the glass component. It is expected that this condensation effect of the nanofiber at the surface contributes to improving the surface conductivity of the materials. ${ }^{34}$ From the data, including the absorption and XRD measurements and the scanning electron microscopy observations, we concluded that CT complexes form between TTF and TCNQ and that charge transport is responsible for the nanofibers of TTF-TCNQ CT complexes, resulting in increased conductivity.

The conductivity was evaluated using the four-point probe method. The probe was pressed onto the material surface, and the surface resistance of one side of the film was measured. The conductivity was calculated as the inverse of the resistance. When the amount of TTF-TCNQ complexes increased, the conductivity increased (Figure 5). These data can be explained by the scanning electron microscopy observations. Increasing the amount of TTF-TCNQ complexes promoted fiber formation at the surface, and the resultant increase in carrier-transporting pathways contributed to the enhancement in conductivity. Notably, the hybrid films exhibited higher conductivities than that of the cast film composed of TTF-TCNQ complexes $\left(9.36 \times 10^{-3} \mathrm{~S} \mathrm{~cm}^{-1}\right)$. It is hypothesized that the assembly of the TTF-TCNQ complexes at the surface contributes to improving the carrier-transport efficiency, leading to enhanced conductivity.

A similar situation was observed in the hybrid upon increasing the proportion of the silica component. Figure 6 presents the influence of temperature on the conductivity of hybrids containing various proportions of silica. Higher conductivities of the hybrids than that of the crystals were observed in the series of plots recorded at $25^{\circ} \mathrm{C}$. The TTF-TCNQ complexes, which are responsible for carrier transport, should be condensed at the surface, leading to an improvement in conductivity. On heating the samples, diverse behaviors were observed. In the absence of the silica component (polymer composite), an increase in conductivity was observed that is consistent with the literature. ${ }^{25}$ In contrast, the conductivity changes decreased on increasing the proportion of the silica component. In HYB50TT16, the conductivity was maintained even at surface temperatures of $>100^{\circ} \mathrm{C}$. In contrast, the conductivity drastically decreased in the absence of the silica component (HYB00TT16), even at $\sim 60^{\circ} \mathrm{C}$.
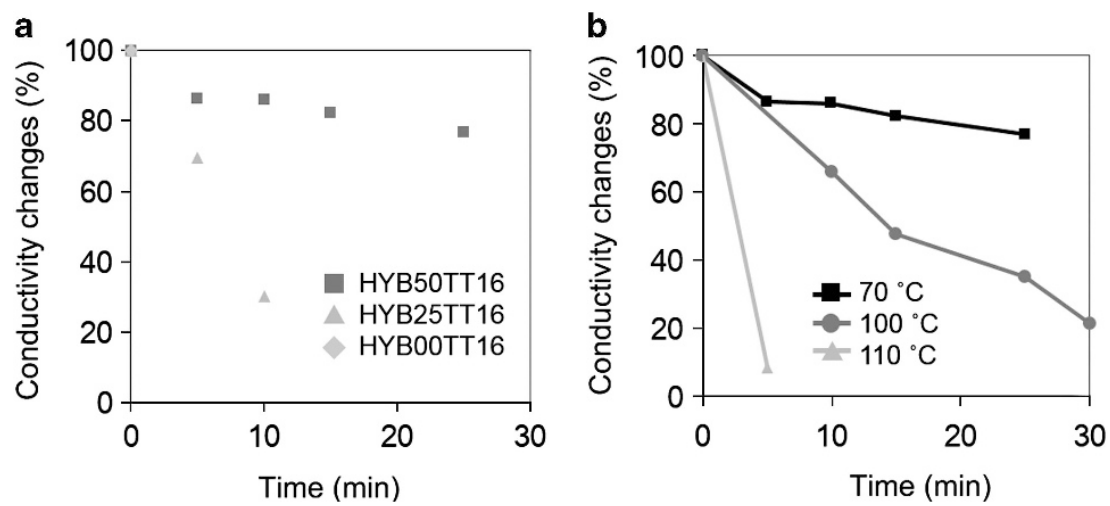

Figure 8 (a) Time courses of the conductivity changes of the hybrids (HYB25TT16 and HYB50TT16) and of the poly(vinylpyrrolidone) (PVP) composite (HYBO0TT16). The samples were heated on a hot plate at $125^{\circ} \mathrm{C}$, and the surface temperature was $70{ }^{\circ} \mathrm{C}$. (b) Time courses of the conductivity changes of HYB50TT16 at various surface temperatures. 
These data clearly indicate that formation of the hybrid enhances the thermal stability of the conductivity. Figure 7 shows thermogravimetric analysis thermograms of the TTF-TCNQ complexes and hybrids. At temperatures of $>200^{\circ} \mathrm{C}$, the thermal stability of the complexes was improved by the formation of the hybrid. The robust silica framework suppressed the molecular motions of the TTF-TCNQ complexes, leading to constant conductivity during heating. These data clearly indicate that the conductive hybrids containing TTF-TCNQ complexes possess high thermal stability.

To demonstrate the thermal stability of the hybrids, we monitored the time courses of the conductivity changes at constant temperatures (Figure 8). The samples were heated on hot plates, and surface temperatures were measured. Then, the conductivity changes were recorded using the four-point probe method. As shown in Figure 8a, a critical loss of conductivity was observed in the PVP composite lacking the silica component (HYB00TT16) after heating at $70{ }^{\circ} \mathrm{C}$ for $5 \mathrm{~min}$. In contrast, HYB25TT16 showed conductivity over the detectable region $\left(<10^{-6} \mathrm{~S} \mathrm{~cm}^{-1}\right)$ after $10 \mathrm{~min}$. Notably, HYB50TT16, which had the highest percentage of silica among the samples, maintained its conductivity even after heating for $25 \mathrm{~min}$. These results indicate that the formation of the hybrid improved the thermal stability of the TTF-TCNQ conductive crystals. In addition, HYB50TT16 showed conductivity after heating at $100{ }^{\circ} \mathrm{C}$ for $25 \mathrm{~min}$ (Figure $8 \mathrm{~b}$ ). These data, including the results shown in Figure 6, clearly indicate that hybrid formation is a valid strategy for enhancing the thermal stability of organic conductive materials.

Finally, we examined the change in conductivity after exposure to water. The hybrids were dipped into deionized water at ambient temperature for $1 \mathrm{~min}$ and then dried in air. Conductivity was monitored under these conditions. Before treatment, the conductivities of the hybrid HYB50TT16 and of the PVP composite HYB00TT16 were determined to be $2.7 \times 10^{-2}$ and $2.5 \times 10^{-3}$ $\mathrm{S} \mathrm{cm}^{-1}$, respectively. The conductivity of the PVP composite was lost after the composite was dipped in water because the films were immediately desorbed from the substrate in water. In contrast, the hybrids maintained conductivity at similar levels after water treatment $\left(5.6 \times 10^{-2} \mathrm{~S} \mathrm{~cm}^{-1}\right)$. The TTF-TCNQ crystals yielded similar results to the PVP composites. These data clearly indicate that hybrid formation enhances durability to moisture. After dipping in water for $2 \mathrm{~min}$, the conductivity of the hybrid HYB50TT16 was not in the detectable range (Supplementary Figure S1).

\section{CONCLUSION}

We present the introduction of TTF-TCNQ complexes into organic inorganic hybrids and describe their properties. In our experiments, three significant results were obtained with respect to hybrid formation. First, silica plays a significant role in the condensation of TTF-TCNQ complexes at the surface of the hybrids, leading to an enhancement in conductivity. Poor compatibility could be responsible for this effect. Second, the silica component improves the environmental resistance of the materials. The conductivity is preserved even after heating and exposure to water. Third, molecular motion is efficiently suppressed in the hybrids. Consequently, conductivity changes during heating are suppressed. These properties could be important not only for extending the application of TTF-based materials but also for designing thermally stable organic devices.

\section{ACKNOWLEDGEMENTS}

This study was partially supported by the Nippon Sheet Glass Foundation for Materials Science and Engineering (for KT). This work was also supported by a Grant-in-Aid for Scientific Research on Innovative Areas 'New Polymeric
Materials Based on Element-Blocks (No. 2401)' (24102013) of The Ministry of Education, Culture, Sports, Science, and Technology, Japan.

1 Kajiwara, Y., Nagai, A. \& Chujo, Y. Red/near-infrared light-emitting organic-inorganic hybrids doped with covalently bound boron dipyrromethene (BODIPY) dyes via microwave-assisted one-pot process. Bull. Chem. Soc. Jpn. 84, 471-481 (2011).

2 Kajiwara, Y., Nagai, A. \& Chujo, Y. Microwave-assisted preparation of intense luminescent BODIPY-containing hybrids with high photostability and solvent resistance. J. Mater. Chem. 20, 2985-2992 (2010).

3 Kajiwara, Y., Nagai, A., Tanaka, K. \& Chujo, Y. Efficient simultaneous emission from RGB-emitting organoboron dyes incorporated into organic-inorganic hybrids and preparation of white light-emitting materials. J. Mater. Chem. C 1, 4437-4444 (2013)

4 Kajiwara, Y., Tanaka, K. \& Chujo, Y. Enhancement of dye dispersibility in silica hybrids through local heating induced by the imidazolium group under microwave irradiation. Polym. J. 46, 195-199 (2014).

5 Yu, Y.-H., Lai, C.-Y., Chen, C.-L. \& Yeh, J.-M. Durable electrochromic coatings prepared from electronically conductive poly(3HT-co-3TPP)-silica hybrid materials. J. Electron. Mater. 35, 1571-1580 (2006).

6 Onoda, M., Moritake, T., Matsuda, T. \& Nakayama, H. Physical properties and application of conducting polypyrrole-silica glass composite films prepared by electrochemical polymerization. Synth. Met. 71, 2255-2256 (1995).

7 Onoda, M., Matsuda, T. \& Nakayama, H. Preparation of polypyrrole-silica glass composite films by sol-gel process and their electrochemical properties. Electr. Eng. Jpn. 120, 1047-1053 (1997).

8 Wei, Y., Yeh, J.-M., Jin, D., Jia, X. \& Wang, J. Composites of electronically conductive polyaniline with polyacrylate-silica hybrid sol-gel materials. Chem. Mater. 7, 969-974 (1995)

9 Lee, Y., Kim, J. \& Son, Y. The preparation of organic/inorganic conducting polymer composite films using in-situ sol-gel process. Polymer (Korea) 23, 443-449 (1999).

10 Bhowmik, K., Pramanik, S., Medda, S. K. \& De, G. Covalently functionalized reduced graphene oxide by organically modified silica: a facile synthesis of electrically conducting black coatings on glass. J. Mater. Chem. 22, 24690-24697 (2012).

11 Watcharotone, S., Dikin, D. A., Stankovich, S., Piner, R., Jung, I., Dommett, G. H. B. Evmenenko, G., Wu, S.-E., Chen, S.-F., Liu, C.-P., Nguyen, S. T. \& Ruoff, R. S Graphene-silica composite thin films as transparent conductors. Nano Lett. 7 , 1888-1892 (2007)

12 de Andrade, M. J., Weibel, A., Laurent, C., Roth, S., Bergmann, C. P., Estournès, C. \& Peigney, A. Electrical conductive double-walled carbon nanotubes - Silica glass nanocomposites prepared by the sol-gel process and spark plasma sintering. Scripta Mater. 61, 988-991 (2009)

13 Matsumura, T., Ochi, M. \& Nagata, K. Thermomechanical properties, phase structure, and conductivity of organic/inorganic hybrid June 2014, Volume 70, Issue 3, pp 517-527 material filled with a conductive filler. J. Appl. Polym. Sci. 90, 1980-1984 (2003)

14 Pokrass, M., Azulay, D., Balberg, I., Atar, N., Gvishi, R. \& Nathan, M. Electrical properties study of multi-walled carbon nanotubes/hybrid-glass nanocomposites. J. Sol-Gel Sci. Technol. 70, 517-527 (2014).

15 Jeon, J., Lee, T. I., Choi, J.-H., Oh, H. S., Kang, J. Y., Chae, S. S., Baik, H. K., Lee, W. \& Myoung, J.-M. Enhanced stability of carbon nanotube transparent conductive film with sol-gel silica layer. Electrochem. Solid-State Lett. 14, K28-K31 (2011).

16 Ulański, J., Jeszka, J. K., Tracz, A., Głowacki, I., Kryszewski, M. \& Laukhina, E. Polymer-(BEDT-TTF) polyiodide composites. Syn. Met. 56, 2001-2006 (1993).

17 Jeszka, J. K., Tracz, A., Wostek, D., Boiteux, G. \& Kryszewski, M. Preparation of organic metal nanocrystals in polymer matrix. Syn. Met. 109, 165-168 (2000).

18 Choi, C. H., Tracz, A., Jeszka, J. K., Botiteux, G., Seytre, G., Ulański, J. \& Kryszewski, $M$. Conductive poly(vinylidene fluoride) reticulate doped with the CT complex TTF-TCNQ. Syn. Met. 37, 181-188 (1990).

19 Tracz, A., Jeszka, J. K., Sroczyńsjam, A., Ulański, J., Plocharski, J., Yamochi, H., Horiuchi, S. \& Saito, G. New transparent, colorless, metallically conductive polymer films and their electrochemical transformations. Syn. Met. 86, 2173-2174 (1997).

20 Tanaka, K., Ishiguro, F. \& Chujo, Y. Transparent conductive films based on polyme composites containing the mixed-valence TTF nanofibers. J. Polym. Sci. A Polym. Chem. 47, 6441-6450 (2009).

21 Jeszka, J. K., Ulański, J. \& Kryszewski, M. Conductive polymer: reticulate doping with charge-transfer complex. Nature 289, 390-391 (1981).

22 Kryszewski, M., Jeszka, J. K., Ulanski, J. \& Tracz, A. Structure and electrical properties of polymers with amorphous and crystalline dopants. Pure Appl. Chem. 56, 355-368 (1984)

23 Tracz, A., Jeszka, J. K., Sroczyńska, A., Kryszewski, M., Schrader, S., Pfeiffer, K. \& Ulański, J. Colourless, transparent conductive polymer films with ultrathin networks of organic crystals. Adv. Mater. Opt. Electron. 6, 330-334 (1996).

24 Tracz, A., Jeszka, J. K., Ulański, J., Pakula, T. \& Rabe, J. P. Structure and optica properties of polycarbonate films with microcrystallites of BEDT-TTF polyiodides. Synth. Met 94, 17-22 (1998).

25 Ulanski, J., Tracz, A. \& Kryszewski, M. Is a percolation threshold in conductive systems below 0.003 possible? J. Phys. D Appl. Phys. 18, 451-459 (1985).

26 Polanowski, P., Ulański, J., Wojciechowski, R., Tracz, A., Jeszka, J. K., Matejcek, S. Dormann, E., Pongs, B. \& Helberg, H. Thin layers of ET2I3 obtained by in situ crystallization-the role of polymer matrix. Synth. Met 102, 1789-1790 (1999). 
27 Tanaka, K., Matsumoto, T. \& Chujo, Y. Synthesis of highly transparent conductive films with strong absorption in near-infrared region based on tetrathiafulvalene-tethered pendant-type polymers. Synth. Met 163, 13-18 (2013).

28 Tanaka, K., Ishiguro, F. \& Chujo, Y. Photo-induced radical generation and self-assembly of TTF into the mixed-valence state in the poly(vinyl chloride) film under UV irradiation. Langmuir. 26, 1152-1156 (2010).

29 Tanaka, K., Ishiguro, F. \& Chujo, Y. Facile preparation of concentration-gradient materials with radical cation and the mixed-valence state of tetrathiafulvalene in conventional polymer films. Langmuir. 26, 10254-10258 (2010).

30 Tanaka, K., Kunita, T., Ishiguro, F., Naka, K. \& Chujo, Y. Modulation of morphology and conductivity of the mixed-valence TTF nanofibers by coexisting organic acid anions. Langmuir. 25, 6929-6933 (2009).

31 Tanaka, K., Matsumoto, T., Ishiguro, F. \& Chujo, Y. Conductivity regulation of the mixed-valence tetrathiafulvalene nanowire/poly(methyl methacrylate) composites using heterogeneous tetrathiafulvalene derivatives. J. Mater. Chem. 21, 9603-9607 (2011).

32 Yamochi, H., Haneda, T., Tracz, A. \& Saito, G. Humidity dependent properties of a transparent conducting film doped with BEDO-TTF complex. Phys. Status Solidi B 249, 1012-1016 (2012)

33 Jeszka, J. K., Tracz, A., Sroczyńska, A., Kryszewski, M., Yamochi, H., Horiuchi, S., Saito, G. \& Ulański, J. Metallic polymer composites with bis(ethylenedioxy)-tetrathiafulvalene salts. Preparation-properties relationship. Syn. Met 106, 75-83 (1999).

34 Tanaka, K., Matsumoto, T., Nakamura, K., Kawabe, S. \& Chujo, Y. Preparation of flexible conductive films based on polymer composites with tetrathiafulvalene nanowires. Synth. Met 180, 49-53 (2013).
35 Polanowski, P., Tracz, A., Ulański, J. \& Dormann, E. Influence of matrix on conductivity properties of crystalline network of $\alpha$-(BEDT-TTF) $)_{2} I_{3}$ in polymer composites. Syn. Met 109, 235-238 (2000).

36 Bellec, N., Lerouge, F., Jeannin, O., Cerveau, G., Corriu, R. J. P. \& Lorcy, D. Auto-organization modulation of tetrasubstituted tetrathiafulvalenes (TTF) in silica based hybrid materials. J. Organometal. Chem 691, 5774-5781 (2006).

37 Bellec, N., Lerouge, F., Pichon, B., Cerveau, G., Corriu, R. J. P. \& Lorcy, D. (Trialkoxysilyl)tetrathiafulvalenes: precursors of organized organic-inorganic hybrid materials by sol-gel chemistry. Eur. J. Org. Chem. 2005, 136-146 (2005).

38 Cerveau, G., Corriu, R. J. P., Lerouge, F., Bellec, N., Lorcy, D. \& Nobili, M. Self-organization of a tetrasubstituted tetrathiafulvalene (TTF) in a silica based hybrid organic-inorganic material. Chem. Commun. 396-397 (2004).

39 Ohnuki, H., Izumi, M., Lenfant, S., Guerin, D., Imakubo, T. \& Vuillaume, D. Deposition of TTF derivative on carboxyl terminated self-assembled monolayers. Appl. Surface Sci. 246, 392-396 (2005).

40 Funabiki, A., Sugiyama, H. Mochida, T, Ichimura, K., Okubo, T., Furukawa, K. \& Nakamura, T. Physical properties of a molecular conductor (BEDT-TTF)213 nanohybridized with silica nanoparticles by dry grinding. RSC Adv. 2, 1055-1060 (2012).

41 Figueras, A., Garelik, S., Caro, J., Cifré, J., Veciana, J., Rovira, C., Ribera, E., Canadell, E., Seffar, A. \& Fontcuberta, J. Preparation and characterization of conducting thin films of molecular organic conductors (TTF-TCNQ). J. Crystal Growth 166, 798-803 (1996).

Supplementary Information accompanies the paper on Polymer Journal website (http://www.nature.com/pj) 